Article

\title{
Exploring the Sports Experiences of Socially Vulnerable Youth
}

\author{
Sabina Super *, Carlijn Q. Wentink, Kirsten T. Verkooijen and Maria A. Koelen \\ Department of Social Sciences, Wageningen University, 6700 EW Wageningen, The Netherlands; \\ E-Mails: sabina.super@wur.nl (S.S.), carlijn.wentink@wur.nl (C.Q.W.), kirsten.verkooijen@wur.nl (K.T.V.), \\ maria.koelen@wur.nl (M.A.K.) \\ * Corresponding author
}

Submitted: 24 January 2017 | Accepted: 10 April 2017 | Published: 29 June 2017

\begin{abstract}
Sports participation is considered beneficial for the development of socially vulnerable youth, not only in terms of physical health but also in terms of cognitive, social and emotional health. Despite the strong belief that sports clubs offer a setting for positive youth development, there is limited knowledge about how socially vulnerable youths experience their participation in these clubs. Interviews were conducted with 22 socially vulnerable youths that play a sport at a local sports club. An inductive content analysis was conducted and three themes were discovered that are included in the positive and negative sports experiences: the extent to which the youths experienced visibility of their skills, the extent to which the youths felt confident while playing their sport, and the extent to which the youths felt that sport was a challenge they liked to take on. More importantly, there was a fragile balance within each of the themes and the sports coaches played an important role in installing and maintaining a supportive environment in which the youths could have meaningful, consistent and balanced sports experiences. It is not self-evident that for socially vulnerable youth sports experiences are positive and supporting.
\end{abstract}

\section{Keywords}

health development; salutogenesis; socially vulnerable youth; sports coach; sports participation

\section{Issue}

This article is part of the issue "Sport for Social Inclusion: Questioning Policy, Practice and Research", edited by Reinhard Haudenhuyse (Vrije Universiteit Brussel, Belgium).

(C) 2017 by the authors; licensee Cogitatio (Lisbon, Portugal). This article is licensed under a Creative Commons Attribution 4.0 International License (CC BY).

\section{Introduction}

The attention that policymakers give to sport as a tool for the personal development of socially vulnerable youth is growing, as researchers argue that the sports setting holds potential for enhancing physical, emotional, social, and cognitive development (Fraser-Thomas, Côté, \& Deakin, 2005). Policymakers and health professionals more and more aim to increase the sports participation rates of young people because they consider that the sports setting is a place where young people can be engaged in meaningful activities and where they can have positive experiences of support and appreciation (Haudenhuyse, Theeboom, Nols, \& Coussée, 2014). In addition, sports participation has often been linked to the development of life skills that can be used in different societal domains (Gould \& Carson, 2008; Hayden et al., 2015). Finally, research has suggested that young people can develop coping abilities through their participation in sport (Tamminen \& Holt, 2012), which they can use in dealing with everyday life challenges. With these ideas in mind, increasing the sports participation of socially vulnerable youth may be a promising way to strengthen their personal development, also because the sports participation rates of socially vulnerable youth are lower than for their average peers (Vandermeerschen, Vos, \& Scheerder, 2015).

In order to understand how socially vulnerable youth may benefit from their participation in sport it is important to investigate how they experience playing a sport 
(Haudenhuyse et al., 2014). Research into sports experiences has often been conducted in athlete samples (Bruner, Hall, \& Côté, 2011; Fraser-Thomas \& Côté, 2009; Kendellen \& Camiré, 2015a). These studies demonstrate that young athletes experience a diversity of developmental experiences as well as negative experiences related to various stressors in the sports setting. Although studies in this area have offered valuable insights, they do not necessarily inform us on how socially vulnerable youth experience sport participation. In fact, very little research has been conducted regarding the sports experiences of socially vulnerable youth. Socially vulnerable youth are characterised as having an accumulated amount of negative experiences with the societal institutions in their lives, which often leads to distorted relationships with those institutions and social disconnectedness (Vettenburg, 1998). These negative experiences with institutions can relate to the family domain (e.g., the parents have financial problems or youths experience domestic violence), to the school domain (e.g., youths are bullied at school), to the judicial system (e.g., after drug use or after a crime) or to the community (e.g., living in a bad neighbourhood with high crime rates). As a result of these negative experiences, socially vulnerable youth are often confronted with feelings of incompetence and rejection. For these youths, sports participation is seen as a tool that can alleviate some of the distorted relationships, when they have positive and supporting experiences within the sports domain, in contrast to the negative experiences they have in other societal domains (Haudenhuyse et al., 2014). Yet, the negative experiences of socially vulnerable youth with the societal institutions in their life may also translate to the sports setting and may influence how they experience their participation in sport. Previous research has shown that the social conditions, such as the sports climate, in the sports setting are important for creating positive experiences and reaching positive outcomes, and that the sports coach is a key-player in creating these social conditions (Cronin \& Allen, 2015; Haudenhuyse, Theeboom, \& Coalter, 2012). However, in the traditional club-based sports setting of many Western countries, many young people sport at local sports clubs that are run by volunteer sports coaches with limited or no formal coaching training. As such, these sports coaches may not always be able to create optimal social conditions. Consequently, given the vulnerable nature of socially vulnerable youth going to local sport clubs, there is reason to believe that these youths' sports experiences may not always be positive.

In recent years, researchers have begun to recognise that research into sports experiences of young people have paid little attention to understanding how they themselves experience their sports participation (Harrist \& Witt, 2015; Holt, Tamminen, Tink, \& Black, 2009). Recognising that including the views of these young people in research is essential (Strachan \& Davies, 2014), several researchers have begun to explore the sports ex- periences of vulnerable young people. A study amongst young people with Attention Deficit Hyperactivity Disor$\operatorname{der}(A D H D)$ showed that the symptoms of ADHD hampered the sports experiences of the participants, for example because they faced difficult interpersonal relationships with sports coaches or peers (Lee, Dunn, \& Holt, 2014). The authors conclude that the sports experiences are complex as the participants also reported benefits from their sports participation. Draper and Coalter (2016) studied the experiences of young males from a deprived South-African community participating in a soccer and life-skills program. They found that the sense of family, safety and belonging were mentioned as the aspects of the program that supported positive development of its participants. The importance of relationships in creating positive experiences has also been emphasised in a study including socially vulnerable youth going to Belgium sports clubs (Haudenhuyse et al., 2014). Given the small number of studies on this topic, this article aims to contribute to existing research by investigating the positive and negative sports experiences of socially vulnerable youth participating in local sports clubs.

\subsection{The Current Study}

In the Netherlands, where the research for this study has been conducted, 10 percent of the youth population received care from youth care organisations because they experience problems in growing up (CBS, 2016). Youth care organisations are increasingly organising care within the youths' close environment and in collaboration with the youths' social network, to prevent that youths receive more expensive and specialised health care. The care that youths receive is specifically adapted to their needs, their abilities, and the environment in which they live in. As the local sports club is one of the pedagogical settings that potentially can support youths in their personal development, the Dutch Ministry of Health, Wellbeing and Sport (VWS, 2011) aims to increase sports participation rates of young people, not only to improve their health, but also to reach wider social and educational outcomes. To enable all youths to join a local sports club, The Youth Sports Fund has been created to offer financial support for membership fees and the purchase of sports cloths and materials (Jansma \& Maks, 2014). As more and more socially vulnerable youth join local sports clubs (Jansma \& Maks, 2014), it is relevant to study how these youths experience their participation in sport.

This study is part of the research project Youth, Care and Sport, that has been set up to study the role of sport in improving the life prospects of socially vulnerable youth (Super, Hermens, Verkooijen, \& Koelen, 2014). The research project aims to 1) understand the relationship between sports participation and youth developmental outcomes; 2) explore how socially vulnerable youth experience their participation in sport and the value they derive from sports participation in a socially vulnerable 
childhood; 3) examine how community sports coaches can create optimal social conditions for the personal development of socially vulnerable youth; and 4) examine the elements of successful and enduring partnerships between youth care organisations and sports organisations. The research project takes a salutogenic approach, that focuses on the main questions 'What creates health?' (Antonovsky, 1979). According to Antonovsky (1979), people are confronted with stressors in their daily lives defined as 'a demand made by the internal or external environment of an organism that upsets its homeostasis' (p. 72). In the salutogenic model of health, stressors can be pathogenic (i.e., negative) but they can also be salutogenic (i.e., positive). Whether stressors become either pathogenic or salutogenic depends on the resources people have available to meet the demands of everyday life and people's ability to deal with stressors, referred to as sense of coherence. Sense of coherence consists of three components (Antonovsky, 1979): the extent to which people experience the world as consistent and structured (comprehensibility); the extent to which people feel that there are resources available to meet the demands of everyday life (manageability); and the extent to which people feel that dealing with the stressors of everyday life is worthy of investment and engagement (meaningfulness). People with a stronger sense of coherence consider stressors more as a meaningful challenge rather than as a threat and, hence, they are better able to select effective coping strategies, resolving tension in a health promoting manner. Previous studies have found a positive association between sports participation and sense of coherence (Ahola et al., 2012; Honkinen, Suominen, Välimaa, Helenius, \& Rautava, 2005), suggesting that the sports setting may provide opportunities for strengthening the sense of coherence as young people are engaged with various stressors and challenges in a meaningful activity. Taking a salutogenic perspective, we aim to better understand the positive and negative sports experiences of socially vulnerable youths participating in local sports clubs.

\section{Methods}

\subsection{Participants and Procedure}

Open interviews were conducted with socially vulnerable youth to educe narratives about the youths' sports experiences (Haden \& Hoffman, 2013). The interviews were conducted with 22 socially vulnerable youths (13 male, 9 female) that participated in local sports clubs. The youths differed in the extent to which they could be labelled as socially vulnerable, ranging from youths living in deprived communities to youths with severe learning or behavioural problems. The youths were contacted via four organisations that work with socially vulnerable youth: two secondary special education schools for young people with severe behavioural or learning problems, one youth care organisation, and one sports club in a socially deprived community. Youth professionals were asked to invite youths to participate in the study based on three inclusion criteria:

1. The youths are between 10 and 18 years old;

2. The youths are socially vulnerable according to Vettenburg's (1998) definition;

3. The youths are member of a sports club or a fitness club.

The youth professionals were informed about the definition of social vulnerability. As the youth professionals had a thorough understanding of the youths' problems, and thus the nature of their vulnerability, they were considered well able to categorise youths accordingly. The researchers were not informed about the exact nature of the youths' problems for ethical reasons. First of all, medical information falls under the client confidentially agreement between medical staff and clients and, therefore, the researchers could not be informed about the youths' medical background by the youth professionals. In addition, to assure that the youths would feel safe during the interviews, no questions were asked about the youths' vulnerable nature. Information about the participating youths can be found in Table 1.

During the interviews, the researchers took into account several ethical considerations in accordance with general ethical guidelines for behavioural and social research as approved by the review board of the Wageningen School of Social Sciences. Via the contact organisation, the researchers informed the youths and their parents about the purpose and set-up of the interview. The parents were asked to inform the contact organisation if they did not want their child to participate in the study. None of the parents disagreed to their child's participation. In addition, the interviewers ascertained that the youths understood that they had the right to leave the study at any point in time without giving a reason, that the interviews would be tape-recorded, and that confidentiality was guaranteed. The interviews were conducted at the participants' chosen location, preferably in the sports environment or another safe environment for the youths. Two researchers (SS and CW) each conducted half of the interviews. All youths received a gift voucher after the interview of 10 euros for an online warehouse.

\subsection{Interview Guide}

The interview guide was based on previous studies in the area of young people's sports experiences regarding the topics that are important in the sports setting (for example, Jakobsson, 2012; Tjomsland et al., 2015). The interviews started with background questions about the youths' sports participation in the past and present, and their motivation for starting to engage in sport (e.g., Why did you chose to play this sport?). These questions were followed by open questions covering several topics such as their experience with their coaches (e.g., Can you tell 
Table 1. Detailed information about the youths.

\begin{tabular}{llll}
\hline Pseudonym & Age & Sex & Current sport \\
\hline Celia & 12 & female & hockey \\
Dacey & 14 & female & gymnastics, horse riding \\
Tamara & 16 & female & dancing \\
lan & 11 & male & hockey \\
Leon & 15 & male & mountain biking \\
Carl & 16 & male & fitness \\
Becky & 13 & female & hockey \\
Harris & 15 & male & soccer \\
Matt & 16 & male & taekwondo \\
Paul & 15 & male & American football, fitness \\
Nathan & 13 & male & hockey \\
Ferdi & 16 & male & fitness \\
Carin & 16 & female & fitness \\
Kaspar & 15 & male & basketball \\
Rachel & 15 & female & dancing \\
Gabriel & 16 & male & cycling, badminton \\
Joyce & 16 & female & walking \\
Jack & 16 & male & female \\
Sanaa & 13 & male & female \\
Vernon & 16 & male & soccer, hockey \\
Daphne & 16 & & hockey \\
Joey & 17 & fitness
\end{tabular}

me about your coach or trainer?), their peers (e.g., What are the people in your team like?), the exercises (e.g., Can you tell me what a regular training looks like?), and (when relevant) competitions (e.g., Can you tell me about the first match you ever played?). The open questions ensured that the youths could share their experiences as they were relevant for them. The interviewer tried to probe for a deeper understanding of the experiences by asking more detailed questions about the experiences.

The interviewers conducted three pilot interviews with youths to evaluate the interview guide. The pilot interviews gave rise to several questions about the suitability of the guide for interviewing socially vulnerable youth. The second step then was to contact a youth professional to discuss the interview guide and strategies to interview socially vulnerable youth. The opportunities to create a safe interviewing climate were also discussed with this youth professional. Consequent to this meeting, the interviewers chose not to use a sheet of paper with interview questions and called the interviews a 'short chat.' It was felt that the use of the term 'interview' and the sheet of interview questions might resemble the characteristics of a therapeutic session and that this could diminish the youths' sense of safety. As a result of the open approach, the interviews varied in terms of duration, depth, and content. The interviews lasted between 10 and 26 minutes. Since the experiences of the youths were very diverse, also in the relatively shorter interviews, all the interviews were considered informative and were taken into account when analysing the data and writing up the results. Some children were better able to express themselves than others, and therefore some interviews were more informative than others.

\subsection{Data Analysis}

The interview recordings were transcribed verbatim and, thereafter, analysed using software for qualitative data analysis (Atlas.ti). Each participant was assigned a pseudonym to guarantee anonymity. An inductive content analysis was conducted to explore the sports experiences of socially vulnerable youth following the guidelines by Elo and Kyngäs (2008). The transcripts were read back and forth by two researchers (SS and CW) to create an initial understanding of the way the youths talked about sports. In the second step, the first author (SS) created initial data-driven codes guided by the main question: Which topics are present in the positive and negative sports experiences? The first author (SS) created a codebook based on the first round of coding, after which the second author (CW) coded all the interviews. The coding was compared between the two authors and was almost identical. Any discrepancies in coding were discussed until agreement was reached. In the third phase, categories were formed by grouping the topics that were present in the positive and negative sports experiences. Although the analysis was inductive in nature, it is important to mention that this study is part of a research project that is inspired by the salutogenic model of health and the work of Antonovsky (1979). The saluto- 
genic model of health was not used to form initial codes, but it did steer the researchers towards considering that stressors can be both pathogenic (negative) and salutogenic (positive) also depending on the youths' resources and their ability to use these resources to deal with the stressors. As such, themes were formed that covered a specific topic in the sports experiences that was mentioned in positive and negative accounts. In the final step, the first author (SS) created a draft report of the interview results that was critically reviewed and compared with the original data by the remaining authors.

\section{Results}

The youths in the interviews described a large diversity in motivation for their sports participation. Having fun was one of the most cited reasons to join a sports club, as well as having fun in getting better in your sports discipline. Yet, also negative accounts were present in the youths' stories. In this section we describe the diversity of the youths' sports experiences. Within each theme we first describe the positive experiences relating to the topic and then the negative experiences.

\subsection{Theme 1: Seeing Your Own Skills}

One source of positive experiences that was frequently mentioned related to the youths' increased understanding of the game and the strategies to improve performance. This was not necessarily related to competition and winning, but also to mastery and improved (sports) skills. Sanaa described how she enjoyed that her new hockey team improved after learning to work together:

Sanaa: It [losing a match] came because we didn't know each other that well. And we didn't know what we were good at. And how you can pass the ball to each other. So we had to learn a lot. And that's when we started working together more and it is going much better now.

In this respect, it is interesting to mention that the youths were very well able to describe the skills they possessed in the sports setting. These were not only sport-technical skills such as ball-handling or shooting techniques, but also broader life skills such as keeping focus, keeping an overview in games, communication skills, and team-work skills. Nathan appreciated playing in competition against various teams, as this helped him to recognise his competencies, stating: 'Yes, then you know what your qualities are.' Most youths were also very well able to describe what they could do to improve the skills that they did not sufficiently possess. The strategies they described were manifold, such as persevering with exercises, asking the sports coach questions, sparring with people who were better than themselves, and asking friends for help. Dacey described her various strategies to learn new gymnastic elements:
Dacey: I just practice on a trampoline and then I will just practice what I have to do. Or I can ask my friends if they can help me, or I will do it in a swimming pool.

In the youths' stories, the sports coaches often played an important role in establishing the visibility of skills. Harris discussed his position on the soccer field and how he, with the help of his sports coach, was able to identify his competencies and weaknesses as a number 10 player:

Harris: In the number 10 position, you need to be able to keep a good overview because you have to look over the field... to whom you should pass the ball. Because you don't want to pass the ball to someone that is offside.

Interviewer: Is that something that you are good at, keeping an overview?

Harris: Yes, I'm good at keeping an overview... but I talk too little. I usually keep my mouth shut and then the sports coach says... you should talk more.

On the other hand, for some youths, the visibility of skills in the sports setting and the ways to develop them were not so clear. Some youths expressed that they did not know how to develop certain skills, stating that it was something that 'goes automatically'. In some instances, the lack of knowing how to develop certain skills could lead to negative experiences. Celia got angry during a hockey training because she tried and failed a number of times in trying to hit a backhand. Asking her what made her so angry, she replied: 'That I can't do it. Even though you keep on trying, I just won't get it'. To Celia, the strategy of 'persevering with exercises' did not help her in learning a new skill.

\subsection{Theme 2: Being Confident in One's Sport}

The stories shared by the youths often incorporated references to (a lack of) confidence, for example in being able to improve their performance or to learn to master new things. The confidence in being able to improve is closely related to the previous theme of being able to see your strengths and weaknesses. However, this theme addresses a broader notion of having confidence beyond mere 'understanding of skills and strategies'. The confidence that the youths expressed in their sport could relate to the individual player (i.e., confidence in having the ability to improve and learn new things), to the sports coach (i.e., the confidence that the sports coach will help to overcome barriers by giving advice and support), and to the team (i.e., the confidence that the team will support the individual to take on new challenges). This confidence was important for the youths to be committed to the sport, the exercises, and competition. Some youths felt confident about being able to learn new things or to take a next step in their level of sport. Tamara, for exam- 
ple, described how she always trusted her talent even though things were sometimes difficult:

Tamara: Well I'm not a quick learner, I'm not fast in picking things up. But if it actually concerns something that I really enjoy doing, then all of a sudden I can do it. For example, if we learn a new [dance] routine...last week....we practised the routine once and I immediately knew the new routine off the top of my head. I guess that you would need some sort of talent to do that.

Other positive accounts related to the confidence and support youths received from their peers. Some youths indicated that the team atmosphere was supportive and positive, which helped them in taking new steps or in persevering when things got tough. Jack, for example, described a situation during a match in which he lost the ball and where his peers coached him in a supportive way. This also increased his confidence that next time he would do it better:

Jack: Yes, they [other team players] will coach me in a positive way. Because when they will coach me in a negative way, this will also negatively affect the match.

Interviewer: And what does that mean, coaching you in a positive way? What do they say or do?

Jack: Then they will say... that next time it will be better if I do it this way or that way. That it doesn't matter, because next time I will get it right.

The sports coach played an important role in establishing this confidence. The youths mentioned the sports coach not only as a source of sport-technical knowledge and advice, but also as a source of constant support. Dacey competed in a gymnastics exercise and felt supported by her sports coach, knowing that he was there to help her whenever she lost track in the routine:

Dacey: But I do really try to do it off the top of my head, but if I forget something then I will look at him [the sports coach]...and then he knows too...if she forgets something then I will do this and this.

Nonetheless, a quarter of the youths also demonstrated a lack of confidence while participating in sport. Several participants felt that there were occasions when they felt unable to master an exercise or a skill, and this could lead to feelings of incapability and uncontrollability. The lack of confidence for some youths arose in comparison to the other players on the team. As Sanaa explained, the difference in level among players reduced her confidence when she compared herself with higher level players:

Sanaa: I don't have much self-confidence when playing hockey. Because I think it's kind of difficult. Espe- cially if you look at the others...they are playing on a higher level. Because I'm only playing on level 2, and some people play on level 4.

Experiencing a lack of confidence or having a sense of uncontrollability could also reduce the youths' willingness to continue in the sport or to keep on trying, as Dacey explained when talking about horse riding:

Dacey: Horse-riding is fun, but every now and then I have to gallop. I can do it, but...the problem is that when I gallop, I get really stressed... because I'm afraid that I will fall off. I can always just cling on so I do not fall off. So yeah, I don't really like that.....And when I don't like it, then I won't do it.

\subsection{Theme 3: Sport as a Nice Challenge}

For many players, the sports settings offered them challenges with which they liked to deal. This was closely linked to the enjoyment that some of the youths experienced when they saw that they were improving in their sport. For example, Carl described how breaking his personal record in weightlifting motivated him to improve continuously:

Interviewer: And can you try to describe what makes fitness so much fun?

Carl: Every time you go...sometimes you can break your own record in kilos. And then you are completely happy. And then you are stuck on that [the record] for a few weeks and then you break your own record again. It's just fun...that you can lift more, that's the most fun.

The lack of a challenge was often perceived as boring and could reduce the motivation to participate in the sports activities. This was often visible when the youths compared their sports activities with the physical education classes in school, which they labelled as boring because they did not need to give their absolute best during these classes. Paul, for example, states:

Interviewer: And well, here at school you play sport as well, right? Physical education classes... how do you like those?

Paul: They are kind of boring.

Interviewer: What makes them boring?

Paul: Well I think the exercises are a bit childish compared to what I do myself [American football].

This theme of 'sport as a nice challenge?' relates strongly to the previous two themes, but it adds a motivational component. Many youths placed a great emphasis on 
getting the best out of themselves, on making sure that they would do whatever it takes to improve, and on persevering even if they failed the first time. Rachel, for example, stated: 'If you really want to do something, then you have to put in effort.' This value of perseverance was shared by many of the youths, and often they also expected others to live up to this value, especially when they played a team sport. Harris clearly described how perseverance was an important value in his soccer team:

Harris: We are sometimes nagging about things in our team. Sometimes there is a guy in our team ehm... well he is a rather good player, but he plays the ball too much. Sometimes he does too much and then the ball is snatched away, and then he has to set things right again. Then we all do our best to set things right again. And then there is someone in our team that messes things up again. That is annoying.

Negative sports experiences were also reported with regards to this value of perseverance, for example when youths felt annoyed when other team players were unable to demonstrate the same perseverance. Following up on the previous quote, Harris talked about how his team responded negatively to those players who did not demonstrate this value:

Interviewer: How does your team respond in those cases?

Harris: Yes... what are you doing?!! Go and run!! What are you doing?! Yelling a bit...like...look at what you are doing! We will lose the match because of this!

The group pressure to get the best out of yourself could be a source of negative sports experiences as well. Although most youths shared the value of perseverance, some felt incompetent in demonstrating this perseverance during the exercises, and this could lead to feelings of rejection and isolation. Competition was especially a setting where these negative sports experiences could arise. Leon's reason for quitting soccer related to the feeling of being rejected in competitions:

Leon: When I was little, I played soccer. But I quit playing soccer because...the other children thought I was a bad soccer player and they didn't want to pass the ball to me. Then I was thinking...I will just quit if they don't want to pass the ball to me.

Similarly, Tamara talked about her dance group in which a few dancers had less experience in dancing and competitions. She indicated that she sometimes felt annoyed when these inexperienced dancers joined the competitions:

Tamara: I get that you join us, just for the dancing....But that you join the competition, you shouldn't do that. You will embarrass the entire group.
The sports coach again played an important role within this theme. The sports coach could create a positive environment in which youths were encouraged to work together and support each other in taking on new challenges, such as competitions. However, in an anecdote shared by Harris, the sports coach negatively contributed to such challenges. Harris described the response of his sports coach when the team was arguing with one of its players because the player did not demonstrate the value of perseverance:

Interviewer: And your trainer? What does he do in those cases?

Harris: My trainer is yelling. We are sitting in the dressing room and you can already tell by his face...he walks around a little and then suddenly he starts yelling. Guys, you need to try harder! Do not lose! Because this is our final match and then...it will all go wrong...then he gets really angry.

\section{Discussion}

In this study we aimed to explore positive and negative sports experiences of socially vulnerable youth. Three themes were discovered that were included in the youths' experiences: the extent to which they experienced visibility of their skills, the extent to which they felt confident while playing their sport, and the extent to which they felt sport was a nice challenge that they liked to take on. There seemed to be a fragile balance within each of these themes and the sports coach was often identified as a key-player in tipping the balance towards positive sports experiences.

The youths reported many positive sports experiences and expressed to enjoy themselves while playing a sport. These positive experiences could originate from different sources: in experiencing visibility of their skills, in being confident while playing a sport, and in engaging in challenges. These results show similarities with the existing literature on fun, enjoyment and sources of motivation in youth sport (Jakobsson, 2012; Tjomsland et al., 2015; Weinberg et al., 2000; Weiss \& Smith, 2002). Tjomsland et al. (2015) found that enjoyment of youth soccer players was related to being with friends, collaborating with team mates, choosing to play the sport, having a supportive coach, and learning new skills and demonstrating mastery of them. Similarly, Jakobsson (2012) interviewed sporting teenagers and found that fun arose in terms of experiencing learning and development, challenging oneself in competition and being involved and engaged with others. As these studies show similarities with our results, it seems that the sources of positive and negative experiences are quite similar for vulnerable and non-vulnerable youths. This is perhaps not surprising, but what is important to add is that, for socially vulnerable youth, the challenges in the sports settings may contain elements that reflect some of the struggles 
they encounter in everyday life (Andrews \& Andrews, 2003; Vettenburg, 1998). For example, sports activities in the secure unit studied by Andrews and Andrews (2003) could exacerbate the youths' anxiety of social comparison, which they were already struggling with in everyday life. In other words, the youths' experiences in everyday life may translate to the sports setting and, as such, can colour their sports experiences. For socially vulnerable youth it is, therefore, important to consider the fragile balance within each of these themes as this influences the extent to which these youths report positive and negative sports experiences. The sports coach is crucial in installing and maintaining a balance in training groups when it comes to these aspects but at the same time is confronted with the imbedded culture of sport to focus on competition, excelling, and individualism (Fraser-Thomas \& Côté, 2009; Super, Verkooijen, \& Koelen, 2016). It is important for sports coaches to create a supportive environment in which youths can experience feelings of success and acceptance (Haudenhuyse et al., 2014; Super et al., 2016).

The three themes that have been identified in this study are closely interconnected. The visibility of skills and the strategies to develop skills (theme 1 ) is one source of having confidence in one's sport (theme 2). For example, knowing how you can learn a new technique in gymnastics can give confidence in one's sport. Similarly, seeing sport as an interesting challenge (theme 3 ) builds on the visibility of skills (theme 1) and the confidence in one's sport (theme 2). In this respect it was found that competition was something that youths could enjoy, especially when they felt they had the skills to play well and when they felt confident in their sport. Moreover, seeing sport as a nice challenge (theme 3 ) may be an important motivator for youths to take on new challenges in the sports setting, which in turn can improve the visibility of skills (theme 1). It is not the purpose of this study to create an order in the importance of the themes, nor to say anything about the sequence in which these experiences may take place. The interconnectedness of the various themes does show that youths may enter a positive or negative vicious circle depending on the extent to which they can be moved towards seeing their skills, having confidence in playing their sport and seeing sport as a nice challenge.

Adding to the complexity, the current study also shows that the elements that can contribute to positive experiences and enjoyment at the same time can contribute to negative experiences and feelings of rejection and isolation. For example, in some instances taking on a challenge was mentioned in positive accounts, whereas in other instances being challenged was described as a negative experience. According to the salutogenic model of health, stressors in themselves are neither negative nor positive (i.e., pathogenic or salutogenic), but depending on people's response towards the stressor, people may move in a negative pathway towards 'unease' and reduced well-being or in a positive pathway towards 'ease' and improved well-being (Antonovsky, 1979). In the case of taking on a challenge, youths that are able and have the resources to deal with the challenge would likely report positive experiences, whereas youths in a similar situation without the ability and the resources to deal with the challenge would likely report negative experiences. The process of dealing with stressors, or as Antonovsky (1979) called it, tension management, results in life experiences that are characterised by a certain degree of overload-underload balance, consistency and socially-valued decision-making. These life experiences in return may strengthen or weaken the sense of coherence; people's capacity to deal with stressors in a health-promoting way. It is thus the combined effect of stressors, resources and people's ability to deal with stressors that results in a salutogenic or pathogenic movement (Vinje, Langeland, \& Bull, 2017). A clear example of a resource in the sports setting is the sports coach. The sports coach can help youths in dealing with a challenge by giving tips on how to handle a specific situation. In this way, the sports coach can assist in creating meaningful, consistent, and balanced experiences during training sessions as these characteristics are known to facilitate learning experiences and to strengthen sense of coherence. In contrast, if these conditions are absent, the sports experiences of socially vulnerable youth are likely to turn pathogenic and possibly lead to breakdown (Antonovsky, 1979). For those youths that the sports setting presents numerous stressors for which they do not have sufficient resources available nor the ability to use the resources to deal with these stressors, the sports experiences may be negative and may push them further down the negative spiral of vulnerability. A study by Super et al. (2016) amongst community sports coaches showed how sports coaches can create optimal conditions for life-skill development from a salutogenic perspective. The sports coaches tried to create meaningful sporting experiences, because these were considered a precondition for engagement and learning. They specifically focused on creating little moments of success and on making sure that the youths felt they belonged to a group (Super et al., 2016). The coaching actions that these sports coaches employed to create little moments of success (i.e., meaningfulness) were directed at making sure that the youths understood 'how things work' (i.e., comprehensibility) and giving them the opportunity to experience mastery (i.e., manageability). Coaching actions directed at comprehensibility were for example to structure the training sessions and to ask questions instead of instructing youths. An example of a coaching action that was directed at manageability was to provide youths with several options to deal with a sportsrelated challenge and allowing youths to find out which option works best. Hence, these coaching actions could help youths by increasing the visibility of their skills, by strengthening their confidence in their sport, and by engaging youths in manageable challenges.

Several authors have argued that, in order to understand how extra-curricular and community-based activ- 
ities, such as sports, may contribute to the personal development of young people, we need to study how youth experience these activities (Dworkin, Larson, \& Hansen, 2003; Hansen, Larson, \& Dworkin, 2003; Haudenhuyse, Theeboom, \& Nols, 2013). A large amount of research has been conducted on the developmental outcomes of sports participation for young people (Fraser-Thomas \& Côté, 2009; Hansen et al., 2003; Kendellen \& Camiré, 2015a). The results of these studies demonstrate a variety of positive outcomes, such as improved social skills, team-work skills, and self-esteem (Holt, Tink, Mandigo, \& Fox, 2008; Kendellen \& Camiré, 2015b). However, it is important to make a distinction between sports experiences, which refer to positive or negative experiences of sport, and the developmental outcomes of those specific experiences. Even though it has been pointed out that naturally occurring sport experiences can promote development and growth (Turnnidge, Côté, \& Hancock, 2014), there is very limited understanding of how sports experiences relate to these outcomes (Hansen et al., 2003; Haudenhuyse et al., 2013). This study has tried to shed a light on this important question by investigating the sports experiences of socially vulnerable youth from a salutogenic perspective. Unfortunately, based on the current data, we were unable to delve into the link between sports experiences and developmental outcomes, as the interviewees were unable to reflect on the developmental outcomes of their sports participation. Future research could try to examine the link between sports experiences and developmental outcomes in greater detail.

\subsection{Study Limitations}

The current study is not without limitations. First of all, because of ethical reasons, the selection of youths for this study was based on the youth professionals' assessment of the socially vulnerable nature of the youths. Youth professionals, that purposively selected youths for this study, were informed about the inclusion criteria and Vettenburg's definition of social vulnerability. Because these youth professionals had detailed knowledge about the youths' problems and backgrounds, they were best able to select youths that met the inclusion criterion of being socially vulnerable. As a result of using Vettenburg's definition of social vulnerability, the youths that are included in the study represent a heterogeneous group, including children with problem behaviour, with alcohol or drug problems or coming from problematised families. Previous research has suggested that subgroups of socially vulnerable youth may have very different sports experiences (Lee et al., 2014). However, based on the interviews, we are not able to draw any conclusions about these differences as we were unable to gather information about the problems of the participants. This limitation arises from some of the conflicting goals that a researcher may be confronted with when conducting research among vulnerable youth groups (Allen, 2002). It is possible that those youths that were most at-risk were not selected by the youth professionals for this study. In addition, because of the selection criterion that the participants should be a member of a local sports or fitness club, we interviewed youths that currently, at least to some extent, attach importance to their participation in sport. These participants might differ from those socially vulnerable youths that are attach less importance to their participation in sport and from those that dropped out of sports. Therefore, we have to refrain from generalising the findings of this study to socially vulnerable youth in general, and specifically to those most at-risk. Further research could involve an adult sample to reflect back on their socially vulnerable childhood in order to investigate the sports experiences in close relation to everyday-life experiences.

Secondly, the interviews were conducted in the form of a casual conversation about how the youths experienced their participation in sport. As the interviewers did not use a sheet of interview questions, questions could be raised about the chosen methodology and the reliability of the results. For example, the order of the questions and the depth in which the various topics were discussed differed in the interviews. This means that in some interviews several topics were discussed more thoroughly than in other interviews, also depending on the youths' willingness and capacity to reflect on a topic. Moreover, as the participating youths may be less inclined or willing to talk about negative experiences, we have to be careful in assuming that the youths' sports experiences were mostly positive. However, the interviewers considered the informal nature of the interviews a strength as it allowed greater insights into the experiences of the youths in their own words than a formal interview and it increased the opportunity to create a safe interviewing climate.

Thirdly, sports participation rates of socially vulnerable youth are lower than of their non-vulnerable peers (Vandermeerschen et al., 2015). Research has demonstrated that socio-economic variables such as household income and parental education are important predictors of children's sports participation (Vandermeerschen et al., 2015; Vella, Cliff, \& Okely, 2014). Also parental support is important, especially for children of a lower age. As a result, it was a challenge to find socially vulnerable youths that actually participated regularly in sport and belonged to a local sports club. Consequently, the sample represents a select group of young people that perhaps differ from other socially vulnerable youths that dropped-out of sport.

\section{Conclusion}

Socially vulnerable youths described their sports experiences in relation to three themes: the extent to which they experienced visibility of their skills, the extent to which they felt confident while playing their sport, and the extent to which they felt sport was a challenge they liked to take. There was a fragile balance within each of the themes that made the sports experiences either 
positive or negative for socially vulnerable youths and the sports coach played an important role in tipping the balance towards positive experiences. Depending on the ability of the sports coach to create meaningful, consistent, and balanced experiences, the youths may benefit from sports participation even beyond the sports setting.

\section{Acknowledgements}

This work was supported by NWO, the Dutch Organisation for Scientific Research, under grant number: 328-98-007.

\section{Conflict of Interests}

The authors declare that they have no competing interests.

\section{References}

Ahola, A. J., Mikkilä, V., Saraheimo, M., Wadén, J., Mäkimattila, S., Forsblom, C., . . . Groop, P. H. (2012). Sense of coherence, food selection and leisure time physical activity in type 1 diabetes. Scandinavian Journal of Public Health, 40(7), 621-628.

Allen, D. (2002). Research involving vulnerable young people: A discussion of ethical and methodological concerns. Drugs: Education, Prevention and Policy, 9(3), 275-283.

Andrews, J. P., \& Andrews, G. J. (2003). Life in a secure unit: The rehabilitation of young people through the use of sport. Social Science and Medicine, 56(3), 531-550.

Antonovsky, A. (1979). Health, stress and coping. San Francisco: Jossey-Bass.

Bruner, M. W., Hall, J., \& Côté, J. (2011). Influence of sport type and interdependence on the developmental experiences of youth male athletes. European Journal of Sport Science, 11(2), 131-142.

CBS. (2016). Jeugdhulp 2015. Den Haag: Centraal Bureau voor de Statistiek.

Cronin, L. D., \& Allen, J. B. (2015). Developmental experiences and well-being in sport: The importance of the coaching climate. Sport Psychologist, 29(1), 62-71.

Draper, C. E., \& Coalter, F. (2016). "There's just something about this club. It's been my family." An analysis of the experiences of youth in a South African sport-for-development programme. International Review for the Sociology of Sport, 51(1), 44-60.

Dworkin, J. B., Larson, R., \& Hansen, D. (2003). Adolescents' accounts of growth experiences in youth activities. Journal of Youth and Adolescence, 32(1), 17-26.

Elo, S., \& Kyngäs, H. (2008). The qualitative content analysis process. Journal of Advanced Nursing, 62(1), 107-115.

Fraser-Thomas, J. L., \& Côté, J. (2009). Understanding adolescents' positive and negative developmental experiences in sport. Sport Psychologist, 23(1), 3-23.
Fraser-Thomas, J. L., Côté, J., \& Deakin, J. (2005). Youth sport programs: An avenue to foster positive youth development. Physical Education and Sport Pedagogy, 10(1), 19-40.

Gould, D., \& Carson, S. (2008). Life skills development through sport: Current status and future directions. International Review of Sport and Exercise Psychology, 1(1), 58-78.

Haden, C. A., \& Hoffman, P. C. (2013). Cracking the code: Using personal narratives in research. Journal of Cognition and Development, 14(3), 361-375.

Hansen, D. M., Larson, R. W., \& Dworkin, J. B. (2003). What adolescents learn in organized youth activities: A survey of self-reported developmental experiences. Journal of Research on Adolescence, 13(1), 25-55.

Harrist, C. J., \& Witt, P. A. (2015). Calling the screens: Self-reported developmental outcomes in competitive basketball. Journal of Adolescent Research, 30(6), 751-778.

Haudenhuyse, R., Theeboom, M., \& Coalter, F. (2012). The potential of sports-based social interventions for vulnerable youth: Implications for sport coaches and youth workers. Journal of Youth Studies, 15(4), 437-454.

Haudenhuyse, R., Theeboom, M., \& Nols, Z. (2013). Sports-based interventions for socially vulnerable youth: Towards well-defined interventions with easyto-follow outcomes? International Review for the Sociology of Sport, 48(4), 471-484.

Haudenhuyse, R., Theeboom, M., Nols, Z., \& Coussée, F. (2014). Socially vulnerable young people in Flemish sports clubs: Investigating youth experiences. European Physical Education Review, 20(2), 179-198.

Hayden, L. A., Whitley, M. A., Cook, A. L., Dumais, A., Silva, M., \& Scherer, A. (2015). An exploration of life skill development through sport in three international high schools. Qualitiative Research in Sport, Exercise and Health, 7(5), 759-775.

Holt, N. L., Tamminen, K. A., Tink, L. N., \& Black, D. E. (2009). An interpretive analysis of life skills associated with sport participation. Qualitative Research in Sport and Exercise, 1(2), 160-175.

Holt, N. L., Tink, L. N., Mandigo, J. L., \& Fox, K. R. (2008). Do youth learn life skills through their involvement in high school sport? A case study. Canadian Journal of Education, 31(2), 281-304.

Honkinen, P. L. K., Suominen, S. B., Välimaa, R. S., Helenius, H. Y., \& Rautava, P. T. (2005). Factors associated with perceived health among 12-year-old school children. Relevance of physical exercise and sense of coherence. Scandinavian Journal of Public Health, 33(1), 35-41.

Jakobsson, B. T. (2012). What makes teenagers continue? A salutogenic approach to understanding youth participation in Swedish club sports. Physical Education and Sport Pedagogy, 19(3), 239-252.

Jansma, K., \& Maks, M. (2014). Businessplan. Ambities en Strategie 2014-2017. Retrieved 31 October, 2016, 
from https://www.jeugdsportfonds.nl/wp-content/ uploads/sites/3/2016/09/Businessplan_Jeugdsport fonds_2014-2017.pdf

Kendellen, K., \& Camiré, M. (2015a). Examining former athletes' developmental experiences in high school sport. SAGE Open, 5(4).

Kendellen, K., \& Camiré, M. (2015b). Examining the life skill development and transfer experiences of former high school athletes. International Journal of Sport and Exercise Psychology.

Lee, H., Dunn, J. C., \& Holt, N. L. (2014). Youth sport experiences of individualswith attention deficit/hyperactivity disorder. Adapted Physical Activity Quarterly, 31(4), 343-361.

Strachan, L., \& Davies, K. (2014). Click! Using photo elicitation to explore youth experiences and positive youth development in sport. Qualitative Research in Sport, Exercise and Health, 7(2), 170-191.

Super, S., Hermens, N., Verkooijen, K. T., \& Koelen, M. (2014). Enhancing life prospects of socially vulnerable youth through sport participation: A mixed methods study. BMC Public Health, 14.

Super, S., Verkooijen, K. T., \& Koelen, M. (2016). The role of community sports coaches in creating optimal social conditions for life skill development and transferability - a salutogenic perspective. Sport, Education and Society.

Tamminen, K. A., \& Holt, N. L. (2012). Adolescent athletes' learning about coping and the roles of parents and coaches. Psychology of Sport and Exercise, 13(1), 69-79.

Tjomsland, H. E., Larsen, T., Holsen, I., Ronglan, L. T., Samdal, O., \& Wold, B. (2015). Enjoyment in youth soccer: Its portrayals among 12- to 14-year-olds. Soccer and Society, 17(6), 827-842.
Turnnidge, J., Côté, J., \& Hancock, D. J. (2014). Positive youth development from sport to life: Explicit or implicit transfer? Quest, 66(2), 203-217.

Vandermeerschen, H., Vos, S., \& Scheerder, J. (2015). Who's joining the club? Participation of socially vulnerable children and adolescents in club-organised sports. Sport, Education and Society, 20(8), 941-958.

Vella, S. A., Cliff, D. P., \& Okely, A. D. (2014). Socioecological predictors of participation and dropout in organised sports during childhood. International Journal of Behavioral Nutrition and Physical Activity, 11(1).

Vettenburg, N. (1998). Juvenile delinquency and the cultural characteristics of the family. International Journal of Adolescent Medicine and Health, 3, 193-209.

Vinje, H. F., Langeland, E., \& Bull, T. (2017). Aaron Antonovsky's Development of Salutogenesis, 1979 to 1994. In M. B. Mittelmark, S. Sagy, M. Eriksson, G. Bauer, J. Pelikan, B. Lindström, \& G. A. Espnes (Eds.), The Handbook of Salutogenesis (pp. 25-40): Springer Open.

VWS. (2011). Programma sport en bewegen in de buurt. The Netherlands: Ministry of Health, Well-being and Sport.

Weinberg, R., Tenenbaum, G., McKenzie, A., Jackson, S., Anshel, M., Grove, R., \& Fogarty, G. (2000). Motivation for youth participation in sport and physical activity: Relationships to culture, self-reported activity levels, and gender. International Journal of Sport Psychology, 31(3), 321-346.

Weiss, M. R., \& Smith, A. L. (2002). Friendship quality in youth sport: Relationship to age, gender, and motivation variables. Journal of Sport and Exercise Psychology, 24(4), 420-437.

\section{About the Authors}

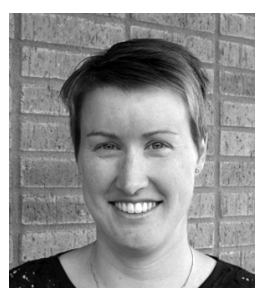

Sabina Super is a PhD researcher at the Health and Society Group of Wageningen University. Her research adopts a salutogenic perspective to understand if and how sport contributes to the personal development of young people. In addition, she focuses on the question how community sports coaches can create optimal social conditions for life skill development.

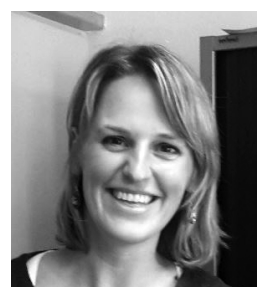

Carlijn Wentink (MSc) is a lecturer and researcher at the Health and Society Group of Wageningen University. Her main focus is on health development in the relationship between people and their built and natural environment, from a social science perspective. Most of her work is inspired by an EcoHealth approach, systems thinking and salutogenesis. Additionally, she works on better designed teaching and learning by working on innovation in education. 


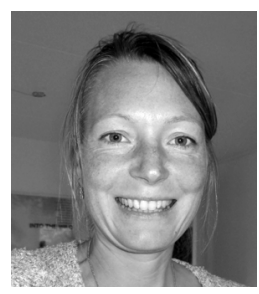

Kirsten Verkooijen is assistant professor at the Health and Society Group of Wageningen University, the Netherlands. She studied Health Sciences with the two specializations Health Education and Health Promotion and Mental Health Sciences at Maastricht University. Hereafter she did her PhD on Identity and health risk behaviour in adolescence at the University of Southern Denmark. Her current research deals with implicit and explicit cognition, social influence, motivation and identity development with a special focus on sport and exercise behaviour.

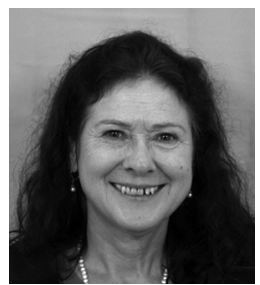

Maria Koelen is Professor and Head of the Health and Society Group of Wageningen University. She has special interest in the social, natural and built environment of health and its interaction with lifestyle, health development and quality of life. Most of her research is based on salutogenesis and the life course perspective. 